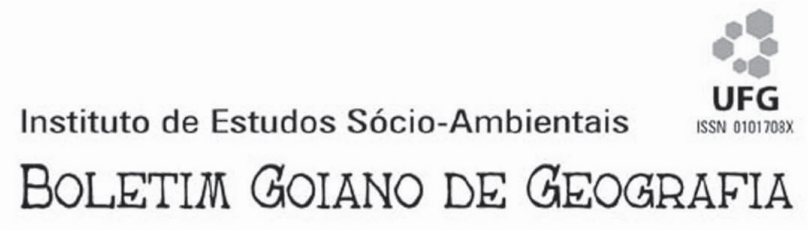

v. 26, n. 2, jul./dez. 2006

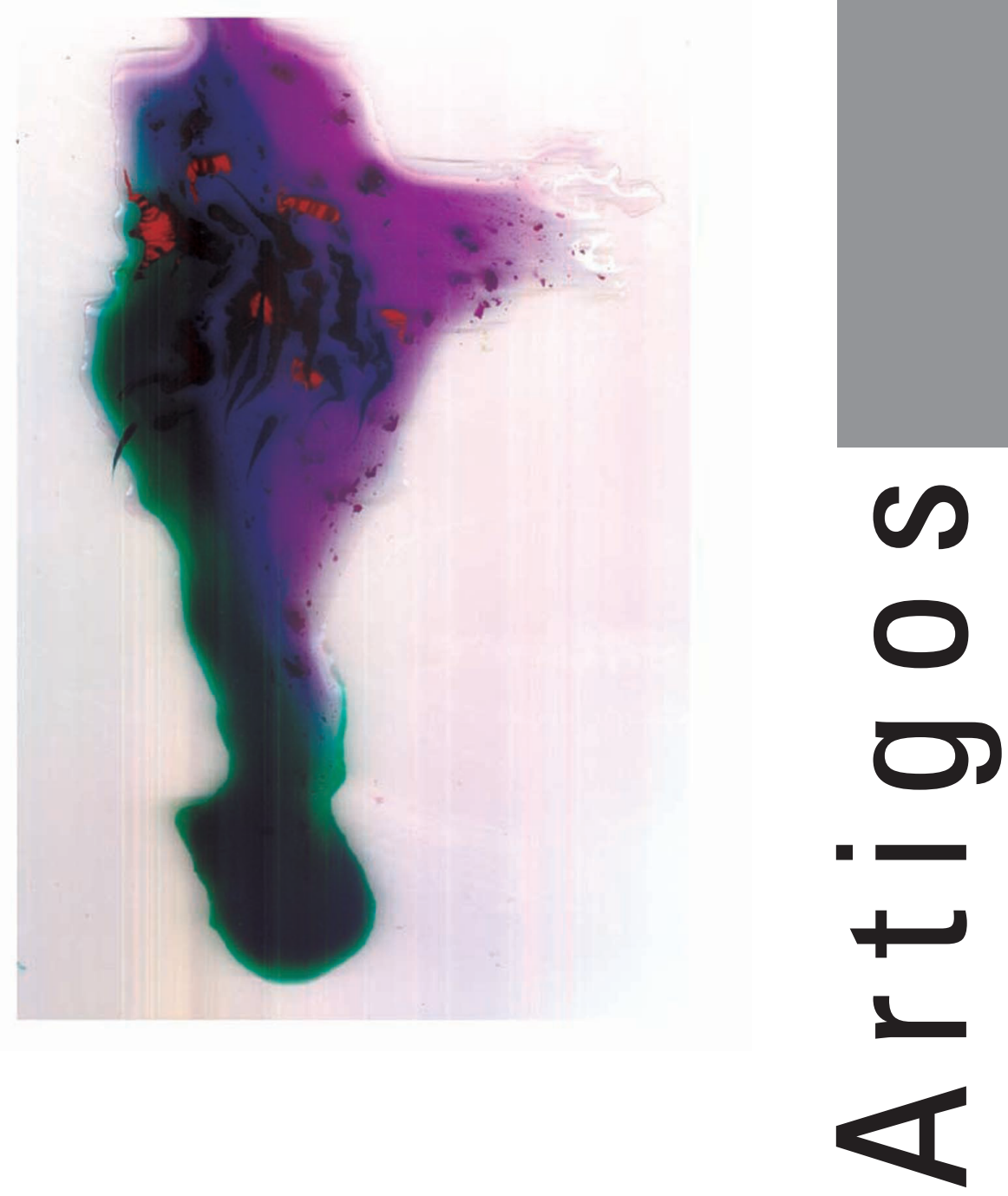




\title{
A TEORIA DA POPULAÇÃO EM MARX
}

\section{THE THEORY OF THE POPULATION IN MARX}

\author{
Nildo Viana - UEG \\ nildoviana@terra.com.br
}

\section{Resumo}

0 presente artigo busca resgatar a teoria da população em Marx. Após observar a contribuição metodológica de Marx para a compreensão da dinâmica populacional e sua crítica a Malthus, apresentamos a teoria da população de Marx e encerramos com uma reflexão sobre sua atualidade, refutando as críticas endereçadas à sua teoria.

Palavras-chaves: teoria da população, exército industrial de reserva, metafísica, dialética, capitalismo.

\section{Abstract}

The present article looks for to rescue the theory of the population in Marx. After observing Marx's methodological contribution for the understanding of the population dynamics and your critic Malthus, we presented the theory of Marx's population and we contained with a reflection about your present time, refuting the critics addressed to your theory.

Key-words: theory of the population, industrial army of reservation, metaphysics, dialetical, capitalism. 


\section{Introdução}

As análises do fenômeno populacional (econômicas, demográficas, geográficas, sociológicas) são, freqüentemente, enriquecidas com a teoria marxista, seja utilizando seu aparato metodológico, seja utilizando as teorias elaboradas por Marx e seus continuadores. No entanto, nem sempre esta contribuição vem sendo interpretada corretamente, pois tanto o método quanto a teoria vêem sendo empobrecidas por alguns dos mais influentes dos auto-intitulados marxistas. Este é o motivo de buscarmos aqui resgatar a contribuição teórico-metodológica de Marx sobre a questão da população.

\section{A contribuição metodológica de Marx}

Iniciemos com sua contribuição metodológica. Marx sempre ressaltou a necessidade de se buscar compreender os fenômenos como totalidades históricas e concretas. Isto quer dizer que, para ele, não se pode entender a dinâmica populacional isolada das demais relações sociais, ou seja, como uma parte desligada do todo. Também não é possível, a partir desta perspectiva metodológica, desconsiderar a historicidade do fenômeno, ou seja, pensar que ele sempre ocorre da mesma forma em qualquer contexto histórico e social e sem que isto lhe traga qualquer transformação.

Marx e Engels chamaram de metafísica a concepção oposta, que retira o fenômeno das relações sociais e da história. Segundo Engels:

\footnotetext{
Para o metafísico, as coisas e suas imagens no pensamento, os conceitos, são objetos isolados de investigação, objetos fixos, imóveis, observados um após o outro, cada qual de per si, como algo determinado e perene. (...). Preocupado com sua própria existência, não reflete sobre sua gênese e sua caducidade; concentrado em suas condições estáticas, não percebe sua dinâmica; obcecado pelas arvores não consegue ver os bosques. (ENGELS, 1990, p. 21)
}

A concepção dialética é radicalmente diferente da metafísica. O método dialético busca compreender a historicidade, o processo de mutação dos fenômenos, e sua inserção num determinado contexto social, o que permite entender sua variabilidade. Engels coloca isto da seguinte forma:

As condições sob as quais os homens produzem e trocam o que foi produzido variam muito para cada país e, dentro de cada país, de geração para geração. Por isso a Economia Política não pode ser a mesma para todos os países nem pra todas as épocas históricas. (ENGELs, 1990, p. 127) 
Daí a necessidade de reconhecer a historicidade:

A Economia Política é, portanto, uma ciência essencialmente histórica. A matéria sobre que versa é uma matéria histórica, isto é, sujeita à mudança constante. Somente depois de investigar as leis específicas de cada etapa concreta da produção e de troca, como conclusão, nos será permitido formular, a título de resumo, as poucas leis verdadeiramente gerais, aplicáveis à produção e à troca, quaisquer que sejam os sistemas. Com isto quer se dizer que as leis, que se aplicam a um determinado sistema de produção ou a uma forma concreta de troca, são válidas também a todos aqueles períodos históricos em que esse sistema de produção ou essa forma de troca se apresentam. (ENGELs, 1990, p. 127)

Aqui Engels coloca que existem elementos ou processos típicos em cada época do desenvolvimento histórico da humanidade e outros que permanecem em várias épocas. Por exemplo, o Estado não existiu sempre. Cada sociedade sem Estado criou suas formas de regularização das relações sociais específicas mas se pode encontrar um processo comum no conjunto destas sociedades e o mesmo ocorre nas sociedades com Estado.

Esta concepção metodológica estará presente na teoria da população elaborada por Marx e é a fonte de sua crítica a Thomas Malthus. A "lei da população” de Malthus é metafísica e Marx contrapõe a ela sua concepção dialética ${ }^{1}$. Vejamos os apontamentos metodológicos de Marx sobre a questão da população para depois apresentar sua crítica a Malthus. Marx enfatiza que uma que "uma lei populacional abstrata só existe para planta e animal, à medida em que o ser humano não interfere historicamente” (MARX, 1988a, p. 191) ${ }^{2}$.

A dinâmica populacional não pode ser compreendida se extraída, arrancada para fora, do conjunto das relações sociais nas quais emerge. Este pressuposto metodológico será seguido por Marx na sua teoria da população, que é, na verdade, uma teoria da dinâmica populacional sob o capitalismo.

\section{Marx crítico de Malthus}

Antes de apresentar a teoria da população em Marx iremos, entretanto, expor a crítica que ele fez a Malthus. A lei da população de Malthus se fundamenta na relação entre "meios de subsistência" e "aumento populacional” (e isto gera sua explicação sobre as causas da fome e da miséria). Segundo Malthus, a população cresce em progressão geométrica $(2,4,8,16 \ldots)$ e a produção de alimentos (meios de subsistência) em progressão aritmética 
$(1,2,3,4 \ldots)$, o que geraria a escassez, a fome. Marx é um severo crítico desta concepção, opondo-lhe tanto a questão metodológica quanto os seus equívocos teóricos derivados de sua concepção metafísica ligada a determinados interesses de classe. Segundo Marx: "A teoria de Malthus (...) é importante em dois aspectos: 1. porque outorgou uma expressão brutal ao brutal modo de pensar do capital; 2. porque afirmou a existência da superpopulação em todas as formas de sociedade” (MARx, 1985, p. 112).

Marx coloca que a concepção de Malthus é "totalmente falsa e pueril" (MARx, 1985, p. 112). Ele realiza algumas críticas à concepção de Malthus, sendo que uma das principais se refere ao seu caráter a-histórico. Marx afirma que Malthus "considera como da mesma natureza a superpopulação nas diferentes fases históricas do desenvolvimento econômico" e que:

Não compreende sua diferença específica e reduz estupidamente essas relações complicadíssimas e mutantes a uma relação, a dois termos, na qual se contrapõe por um lado à reprodução natural do homem, por outro a propagação natural dos vegetais (os meios de subsistência), como se tratasse de duas séries naturais, das quais uma aumenta geometricamente, a outra aritmeticamente. Desta forma, transforma as relações historicamente diferentes em uma relação numérica abstrata existente somente na fantasia, que não se fundamenta nem nas leis naturais nem nas leis históricas. (MARx, 1985, p. 112)

Aqui Marx critica o caráter abstrato-metafísico, portanto a-histórico, da lei populacional malthusiana, pois a população possui uma dinâmica diferente em sociedades e épocas diferentes. Além disso, o crescimento populacional não ocorre em ritmo geométrico. Marx continua sua crítica a Malthus:

O idiota supõe com isso que a multiplicação do homem é um processo puramente natural, que requer limitações, freios externos pra não se efetuar em uma proporção geométrica. Esta população geométrica constitui o processo natural da reprodução humana. Na história verá que a população se desenvolve em proporções muito diferentes e que a superpopulação constitui igualmente uma relação historicamente determinada, de nenhum modo determinada por números ou pelo limite absoluto da produtividade dos meios de subsistência, mas mediante limites postos por determinadas condições de produção. (MARX, 1985, p. 112-113) $)^{3}$

Assim, Malthus cria um "homem abstrato", produto de sua abstração metafísica que coloca o homem fora da história, das relações sociais. O "homem malthusiano" está submetido à leis abstratas (metafísicas). Ele troca as leis históricas ${ }^{4}$ por leis abstrato-metafísicas: 
É Malthus, pois, que faz abstração destas leis históricas dos movimentos da população, leis que são, em tais circunstâncias, a história da natureza humana; leis naturais, mas que são leis naturais do homem em determinado desenvolvimento histórico, com um determinado desenvolvimento das forças produtivas, condicionado pelo seu próprio processo histórico. O homem malthusiano abstraído do homem historicamente determinado, só existe no cérebro de Malthus, assim como, por fim, o método de reprodução geométrica corresponde a este homem natural malthusiano. A história real, pois, se lhe apresenta de tal modo que a reprodução de seu homem natural não é uma abstração do processo histórico, da reprodução real, mas, pelo contrário, a reprodução real resulta ser uma aplicação da teoria malthusiana. (MARX, 1985, p. 113)

É devido a isto que Malthus irá considerar que a produção da superpopulação só pode ser limitada por "freios externos", ou seja, se seu esquema abstrato não funciona tal como ele o concebe, isto se deve a fatores externos. O fator externo encontrado por Malthus é a produção dos meios de subsistência.

Além disso, Malthus relaciona de forma simplista um determinado quantum de homem com determinado quantum de meios de subsistência. Marx coloca que David Ricardo já havia refutado tal tese, ressaltando que não é a quantidade de meios de subsistência e sim os "meios de emprego" (demanda por força de trabalho) que produz a população excedente. A criação de "trabalhadores excedentes" (homens desprovidos de propriedade e que precisam trabalhar para sobreviver) "é própria da época do capital" (MARx, 1985, p. 114). Marx acrescenta a isto o fato de que a produção dos meios de subsistência não cresce em progressão aritmética, tal como coloca Malthus ${ }^{5}$.

Portanto, Marx realiza uma crítica à lei da população de Malthus e em oposição a ela irá apresentar sua própria teoria da população. Ele irá analisar a dinâmica populacional no interior do modo de produção capitalista, pois cada modo de produção possui sua dinâmica populacional própria.

\section{Capitalismo e população}

O processo de acumulação de capital está intimamente ligado à dinâmica populacional. Marx ressalta que o crescimento do capital provoca um crescimento da demanda por força de trabalho. O processo de acumulação capitalista significa uma ampliação do mercado, dos investimentos, etc. As 
necessidades da acumulação capitalista podem superar o crescimento do número de trabalhadores, e, isto ocorrendo, mantidas as mesmas condições do processo de acumulação, cria-se a tendência de elevação dos salários.

A reprodução da força de trabalho, que incessantemente precisa incorporar-se ao capital como meio de valorização, não podendo livrar-se dele e cuja subordinação ao capital só é velada pela mudança dos capitalistas individuais a que se vende, constitui de fato um momento da própria reprodução do capital. A acumulação do capital é, portanto, multiplicação do proletariado. (MARX, 1988a, p. 179)

Este processo, sem dúvida, diminui a taxa de exploração da força de trabalho e faz decrescer a acumulação. Mas junto com o decréscimo, diz Marx, desaparece sua determinação, ou seja, a demanda pela força de trabalho. O próprio processo de acumulação capitalista elimina os obstáculos que ele mesmo cria. O salário, com a diminuição da procura por força de trabalho, decresce.

No primeiro caso, não é a diminuição no crescimento absoluto ou proporcional da força de trabalho ou da população operária que torna o capital redundante, mas, ao contrário, é o aumento do capital que torna insuficiente a força de trabalho explorável ou, antes, o seu preço. São esses movimentos absolutos na acumulação do capital que se refletem como movimentos relativos na massa da força de trabalho explorável e, por isso, parecem dever-se ao movimento próprio desta última. (MARx, 1988a, p. 183)

Marx coloca que a dinâmica populacional reside basicamente aí, ou seja, na taxa de exploração que altera a demanda pela força de trabalho. No entanto, com o desenvolvimento capitalista, há um crescimento de produtividade e este tem com uma de suas condições de possibilidade o desenvolvimento tecnológico e a incorporação de um quantum maior de meios de produção no processo de trabalho. Marx chama isto de "composição técnica do capital”, que se caracteriza pelo aumento de capital constante (meios de produção) em relação ao capital variável (massa de força de trabalho). Isto provoca, evidentemente, uma diminuição na demanda pela força de trabalho.

Como a demanda de trabalho não é determinada pelo volume do capital global, mas por seu componente variável, ela cai progressivamente com o crescimento do capital global, ao invés de, como antes se pressupôs, crescer de modo proporcional com ele. Ela cai em relação à grandeza do capital global e em progressão acelerada com o crescimento desta grandeza. Com o crescimento do 
capital global na verdade também cresce seu componente variável, ou a força de trabalho nele incorporada, mas em proporção continuamente decrescente. (MARX, 1988a, p. 190)

Marx coloca que isto produz "uma população trabalhadora adicional relativamente supérflua ou subsidiária” que não é empregada pelo capital. Marx conclui:

Com a acumulação de capital produzida por ela mesma, a população trabalhadora produz, portanto, em volume crescente, os meios de sua própria redundância relativa. Essa é uma lei populacional peculiar ao modo de produção capitalista, assim como, de fato, cada modo de produção histórico tem suas leis populacionais particulares, historicamente válidas. (MARX, 1988a, p. 191)

Esta população "excedente" Marx chama de "superpopulação relativa”. "Ela constitui um exército industrial de reserva disponível, que pertence ao capital de maneira tão absoluta, como se ele o tivesse criado à própria custa” (MARX, 1988a, p. 191) ${ }^{6}$.

Esta superpopulação relativa transforma-se em uma "alavanca da acumulação capitalista”, tornando-se condição de possibilidade de existência do modo de produção capitalista. Qual é a importância desta "superpopulação relativa” para a acumulação capitalista? Isto ocorre devido ao processo de constituição e desenvolvimento do capitalismo. O processo de constituição do capitalismo foi proporcionado pela industrialização que necessitava de uma força de trabalho disponível. No entanto, não seria possível esperar o crescimento absoluto e natural da população e por isso a força de trabalho proletária foi criada à força através da expropriação dos camponeses (no caso clássico da Inglaterra). O desenvolvimento capitalista, no entanto, passado seu período de constituição, altera sua relação com a força de trabalho. O ciclo industrial assume grande importância para compreender esta relação.

O curso de vida característico da indústria moderna, sob a forma de um ciclo decenal, interrompido por oscilações menores, de vitalidade média, produção a todo vapor, crise e estagnação, repousa na contínua constituição, na maior ou menor absorção e na reconstituição do exército industrial de reserva ou superpopulação. Por sua vez, as oscilações do ciclo industrial recrutam a superpopulação e tornam-se os mais enérgicos agentes de sua reprodução. (MARX, 1988a, p. 192)

O exército industrial de reserva e a força de trabalho empregada variam com o ciclo industrial, influindo assim sobre os salários: 
Os movimentos gerais dos salários são exclusivamente regulados pela expansão e contração do exército industrial de reserva, que correspondem à mudança periódica do ciclo industrial. Não são, portanto, determinados pelo movimento do número absoluto da população trabalhadora, mas pela proporção variável em que a classe trabalhadora se divide em exército ativo e exército de reserva, pelo acréscimo ou pelo decréscimo da dimensão relativa da superpopulação, pelo grau em que ela é ora absorvida, ora liberada. (MARX, 1988a, p. 195)

A dinâmica do capital, portanto, é o que gera a proporção entre população empregada e superpopulação relativa e esta última cumpre um papel fundamental para a acumulação capitalista, que é o de pressionar os salários para baixo.

Segundo Marx, a superpopulação relativa possui três formas: líquida, latente e estagnada. A acumulação capitalista provoca a necessidade crescente de força de trabalho, embora em proporção cada vez menor em relação ao capital constante. Além disso, há o desgaste da força de trabalho. Isto produz a superpopulação relativa em sua forma líquida. A demanda pela força de trabalho cresce e seu desgaste também e isto cria a necessidade de crescimento absoluto (vegetativo) de certos setores da população trabalhadora. Marx cita o exemplo dos trabalhadores da grande indústria, cuja duração de vida é mais curta, e isto provoca a necessidade de aumento da população trabalhadora:

O crescimento absoluto dessa fração do proletariado exige uma forma que aumente o número de seus elementos, ainda que estes se desgastem rapidamente. Portanto, rápida renovação das gerações de trabalhadores (a mesma lei não vale para as demais classes da população). Esta necessidade social é satisfeita mediante casamentos precoces, conseqüência necessária das condições em que vivem os trabalhadores da grande indústria, e mediante o prêmio que a exploração dos filhos dos trabalhadores acrescenta à sua produção. (MARX, 1988a, p. 1987)

A superpopulação relativa constante é constituída pela população trabalhadora rural, que com o processo de mudança tanto no campo quanto na cidade, tende continuamente a se transferir para o mundo urbano $^{8}$ e a ingressar, em alguns casos, no proletariado urbano e, em outros, no exército industrial de reserva.

A superpopulação relativa estagnada representa uma parte ativa do exército de trabalhadores, mas com ocupações irregulares. Ela fornece uma reserva inesgotável de força de trabalho ao capital.

Sua condição de vida cai abaixo do nível normal médio da classe trabalhadora, e exatamente isto faz dela uma base ampla para certos ramos de exploração do capital. É caracterizada pelo máximo do tempo de serviço e mínimo de salário. 
Sob a rubrica de trabalho domiciliar, já tomamos conhecimento de sua principal configuração. Ela absorve continuamente os redundantes da grande indústria e da agricultura e notadamente também de ramos industriais decadentes em que o artesanato é vencido pela manufatura e esta última pela produção mecanizada. (MARx, 1988a, p. 199)

Marx ainda apresenta uma outra camada da superpopulação relativa, a que "habita a esfera do pauperismo". Esta seria dividida em três categorias:

Os desempregados capazes de trabalhar; os filhos dos pobres e os órfãos; enfim, as vítimas da indústria: doentes estropiados, viúvas, trabalhadores idosos e trabalhadores desqualificados. (BELLON, 1975, p. 44)

Com o crescimento da acumulação capitalista, cresce o exército industrial de reserva ou, em outras palavras, como o aumento da riqueza há o aumento da pobreza.

\section{A atualidade da teoria da população em Marx}

Qual é o alcance e a validade desta teoria da população na atualidade? A teoria da população em Marx pode ser questionada sob os mais variados aspectos. O primeiro questionamento pode se encontrado no fato de Marx abordar o crescimento migratório e vegetativo apenas da população trabalhadora. Um segundo questionamento se refere ao fato de que sua análise se referia ao período do capitalismo concorrencial e não do período posterior, do capitalismo oligopolista (ou monopolista). Por fim, um terceiro questionamento se refere às diferenças entre a dinâmica populacional nos países capitalistas superdesenvolvidos (imperialistas, o chamado "primeiro mundo”) e os países capitalistas subordinados ("terceiro mundo”) não abordadas por Marx.

Em primeiro lugar, devemos deixar claro que a teoria da população elaborada por Marx ficou incompleta. Ela foi exposta, principalmente, em O Capital, uma obra inacabada ${ }^{9}$. Marx planejava escrever outros volumes de $O$ Capital, tratando de elementos não abordados nos primeiros volumes, tal como sobre as classes sociais (assunto sobre o qual escreveu uma página, incluída no quinto volume por Engels) e o Estado. Além disso, O Capital focaliza o modo de produção capitalista e por isso Marx centrou-se nas suas duas classes sociais fundamentais: a classe capitalista (burguesia) e a classe operária (proletariado). 
Após estas considerações iniciais podemos explicar por qual motivo Marx centrou sua atenção na população trabalhadora. Ele buscou analisar a dinâmica populacional do proletariado e também da superpopulação relati$\mathrm{va}^{10}$, por esta estar envolvida, determinada e ligada ao processo de acumulação capitalista. O que interessa para a acumulação capitalista é a produção e reprodução da força de trabalho (proletariado) e do exército industrial de reserva (lumpemproletariado, segundo nossa conceituação), pois ele não só é uma reserva de força de trabalho para quando o capital necessitar de mais trabalhadores como também é uma pressão constante para o decréscimo dos níveis salariais. É por esse motivo que Marx centrará sua atenção na dinâmica populacional da classe trabalhadora. De qualquer forma, como esta constitui a maioria da população e o seu crescimento (absoluto e proporcional) é maior do que o de qualquer outra classe social (ou mesmo o conjunto das demais classes sociais), fica evidente a importância desta análise para a compreensão da dinâmica populacional geral no capitalismo.

A explicação que Marx apresenta sobre o crescimento migratório da população trabalhadora se encontra no deslocamento da força de trabalho e sobre o crescimento vegetativo (absoluto) se localiza na tendência das camadas mais pobres em possuir um índice maior de procriação (devido suas condições de vida, tal como o casamento precoce ${ }^{11}$ ). Tal como colocamos anteriormente, outras determinações atuam sobre o fenômeno, de acordo com o princípio metodológico de Marx segundo o qual o concreto é o resultado de suas múltiplas determinações (veja, VIANA, 2006). No entanto, as demais determinações ocorrem na esfera das formas de regularização ("superestrutura”) que Marx, por focalizar o modo de produção capitalista, deixou de lado. Sendo assim, para tomar apenas um exemplo, a "expansão barata e rápida da higiene social" que diminuiu a taxa de mortalidade (Plum, 1979, p. 202), não foi abordada por Marx por ser um fenômeno que ocorre na esfera das formas de regularização, sendo uma política estatal, embora mantenha relações com a acumulação capitalista. Além disso, a política estatal voltada para a higiene social se desenvolveu sobretudo no século 20, e nos países capitalistas subordinados a partir, principalmente, da segunda metade deste século ${ }^{12}$. Assim, o crescimento absoluto (vegetativo) da população trabalhadora tem outras determinações que não contradizem a teoria de Marx mas tão-somente lhe dotam de maior concreção.

O segundo questionamento à teoria da população em Marx se refere ao fato dele ter abordado o capitalismo na época competitiva e não na época oligopolista. José Nun (1978), por exemplo, reconhece a validade da teoria 
de Marx mesmo na época oligopolista (ou monopolista), mas considera sem sentido, pois:

Continuar tratando todo o excedente de população como se constituísse um exército industrial de reserva desde que, em sua maioria, não transcenderá o estado de mero fator virtual a respeito da organização produtiva dominante. (Nun, 1978, p. 98)

É por isso que Nun enfatiza a distinção entre superpopulação relativa (existente em vários modos de produção) e exército industrial de reserva (existente apenas no capitalismo), o que é correto. Porém, desta distinção oriunda da historicidade do conceito de exército industrial de reserva, ele chega à conclusão equivocada de que no capitalismo a distinção continua existindo. Para Marx, superpopulação relativa e exército industrial de reserva são, no capitalismo, a mesma coisa. Nun busca encontrar tal distinção na idéia de "função": o exército industrial de reserva teria uma funcionalidade direta, que é proporcionar força de trabalho durante o ciclo industrial ascendente e nas ocasiões de "súbita expansão do capital", e indireta, que é pressionar o proletariado a trabalhar mais e aceitar salários mais baixos. Segundo Nun, no capitalismo monopolista a superpopulação relativa em sua totalidade deixa de ter esta funcionalidade (veja citação acima) e daí ele distingue entre superpopulação relativa funcional (o exército industrial de reserva) e "disfuncional" (que ele denomina "massa marginal") ${ }^{13}$.

Porém, a concepção de Nun não consegue comprovar que tal distinção contribui para um melhor entendimento da superpopulação relativa e nem que a chamada "massa marginal" seja disfuncional. Distinguir entre "exército industrial de reserva" e "massa marginal" em nada contribui para compreender a superpopulação relativa, pois não há nenhuma fronteira que separe estas suas supostas partes e a elaboração de tal distinção conceitual abre portas para a reificação dos termos (no caso, de exército industrial de reserva e massa marginal) criando uma ilusão de demarcação que, no fundo, é inexistente. Além disso, a suposta "massa marginal” não é disfuncional e tal idéia só tem sentido numa concepção metafísica, que desconsideraria o caráter histórico, dinâmico, desta parte da população e provocaria o seu isolamento, desligando-a da totalidade concreta, procedimento tipicamente não-dialético.

A suposta "massa marginal" mantém a "funcionalidade indireta" apontada por Nun - pressionar os trabalhadores a trabalharem mais e aceitarem salários mais baixos - visto que é impossível distinguir quem faz parte do exército industrial de reserva e quem faz parte da "massa marginal", sem 
falar que tal exercer tal função basta existir desempregados, independentemente de serem aproveitados ocasionalmente ou efetivamente ou não. Além disso, também permanece a funcionalidade direta, pois com o ciclo industrial ascendente ou súbita expansão do capital há um uso de contingentes do exército industrial de reserva, o que faz com que o contingente não-utilizado fique "na fila" esperando uma absorção no mercado de trabalho (e isto torna ainda mais visível sua "funcionalidade indireta"). Por isso, superpopulação relativa e exército industrial de reserva são, no capitalismo, a mesma coisa, e compõem o que chamamos lumpemproletariado.

O terceiro questionamento à teoria da população de Marx se encontra na diferença existente na dinâmica populacional nos países capitalistas imperialistas e nos países capitalistas subordinados. O crescimento absoluto da população diminuiu nos primeiros e "disparou" nos segundos. Sem dúvida, Marx não abordou tal processo de diferenciação, ocorrido muito tempo depois dele ter elaborado sua teoria. O desenvolvimento histórico refuta, então, a teoria da população de Marx? Não, pois pode ser integrada nela desde que se leve em consideração as mudanças históricas. O processo de pressão dos trabalhadores nos países capitalistas imperialistas ${ }^{14}$ proporcionou um recuo da classe capitalista e promoveu o chamado "Estado de Bem Estar Social", com baixos índices de desemprego. No entanto, o desemprego diminuiu mas não acabou nestes países ${ }^{15}$.

Nos países capitalistas subordinados, o processo de industrialização tardia não só efetivou a formação de um proletariado concentrado em algumas regiões e um lumpemproletariado (exército industrial de reserva) numeroso, como também se viram numa situação desvantajosa no mercado mundial, já dominado pelas grandes potências. Desta forma, o crescimento industrial teve que suportar limitações e isto promoveu um grande contingente de exército industrial de reserva. O desenvolvimento tecnológico superior dos países imperialistas em relação aos países subordinados, por sua vez, produzia uma enorme transferência de mais-valor, devido ao diferencial na composição orgânica do capital derivado daí (VIANA, 2001) e é isto que permitiu o Estado de Bem Estar Social sem comprometer a acumulação capitalista nos primeiros.

Obviamente, isto explica a formação da superpopulação relativa e as diferenças nacionais, mas não a diferença no crescimento absoluto da população nestes dois blocos de países. Mas aqui, além da asserção de Marx e Adam Smith, segundo a qual as famílias pobres tendem a ter um índice maior de procriação, é preciso recordar que o capitalismo subordinado é 
um mercado consumidor do capitalismo imperialista e que os avanços da medicina, etc., são transferidos para eles, o que contribui com a diminuição de sua taxa de mortalidade e aumenta a expectativa média de vida. Isto tudo leva a um crescimento absoluto da população nos países capitalistas subordinados.

Deste modo, observamos que a teoria da população de Marx não foi refutada pelo desenvolvimento histórico e que as mudanças históricas na dinâmica populacional podem ser compreendidas lançando mão de sua teoria e, principalmente, de seu método, que permitem integrar tais mudanças na análise e assim compreendê-las.

\section{Notas}

1 Marx, sem dúvida, não colocava entre ele e Malthus apenas uma diferença teórica e metodológica, mas fundamentalmente uma diferença de perspectiva de classe.

2 "Marx nega, (...) que a lei da população seja a mesma em todos os tempos e em todos os lugares. Ele assegura, pelo contrário, que cada estágio de desenvolvimento tem uma lei demográfica própria” (autor anônimo. Apud. MARx, 1988b, p. 24).

3 Marx também cita alguns exemplos sobre as diferenças históricas sobre o desenvolvimento populacional: "uma superpopulação de atenienses livres que se transformam em colonos difere consideravelmente de uma superpopulação de operários que se transformam em internos das casas de trabalho. Da mesma forma difere a superpopulação mendicante que consome em um monastério o mais-produto do mesmo, da que se forma em uma fábrica" (MARX, 1985, p. 113).

4 "A idéia de lei se fundamenta principalmente na regularidade, na repetição, na permanência e por isto a lei de que Marx (...) fala não é bem uma lei. Na verdade, o que ele busca descobrir são as determinações e tendências de um fenômeno social” (VIANA, 2006, p. 89). Assim, quando Marx fala em "leis históricas e naturais" da população, ele se refere às determinações deste fenômeno.

5 “Darwin não viu que derrubou a teoria de Malthus, ao descobrir a progressão 'geométrica' no reino animal e vegetal. A teoria de Malthus baseia-se em contrapor a progressão geométrica humana de Wallace à quimérica progressão 'aritmética' dos animais e plantas. Na obra de Darwin, por exemplo a propósito da extinção de espécies, está pormenorizada (abstraímos o seu princípio fundamental) a refutação da história natural à teoria malthusiana” (MARX, 1983, p. 552).

6 José Nun (1978) critica os autores que confundem "superpopulação relativa" e "exército industrial de reserva", tais como Paul Swezzy e Oskar Lange: "enquanto o conceito de exército industrial de reserva corresponde à teoria particular do modo de produção capitalista, os conceitos complementares de população adequada e superpopulação relativa pertencem à teoria geral do materialismo histórico" (Nun, 1978, p. 77). Em outras palavras, o exército industrial de reserva só existe no capitalismo e por isso o uso deste conceito tem sua validade histórica restrita a este modo de produção particular, enquanto que superpopulação relativa existe em outros modos de produção e sua validade histórica é, portanto, mais ampla e ultrapassa os marcos da sociedade capitalista. 
7 Marx aqui, deixando de lado alguns aspectos, concorda com Adam Smith: "A pobreza, embora sem dúvida desencoraje, nem sempre impede o casamento. Parece mesmo favorecer a procriação... A esterilidade, tão freqüente nas mulheres da alta sociedade, é muito rara nas das camadas inferiores...” (apud. MArx, Vol. 2. 1983, p. 654).

8 Uma parte permanece no campo, como "lumpemproletariado camponês", segundo expressão de Marx em outra obra (MARx, 1986).

9 Como sabemos, apenas o volume um desta obra foi publicada durante a vida de Marx e os demais volumes foram organizados por Engels e Kautsky. Os Grundrisse, esboços de O Capital, por sua vez, foi organizado e publicado por Riazanov.

10 Para quem ler a edição portuguesa de O Capital, verá que Marx considerou o lumpemproletariado como apenas uma parte, a submetida mais cruelmente ao pauperismo (delinqüentes, prostitutas, etc.) desta superpopulação relativa. No entanto, no original inglês utilizou, na verdade, a expressão "classes perigosas". Em outras obras, quando se refere ao lumpemproletariado, amplia o conceito. Fanon (1979), ampliou este conceito, incluindo nele o que Marx denominou superpopulação relativa, ou seja, a totalidade dela. Concordamos com este posicionamento de Fanon e por isso consideramos o lumpemproletariado como equivalente a "exército industrial de reserva", isto é, o conjunto da superpopulação relativa constituída pelo capitalismo.

11 "De fato, não só a massa de nascimentos e óbitos, mas também a grandeza absoluta das famílias está em proporção inversão ao nível do salário, portanto, à massa dos meios de subsistência de que as diferentes categorias de trabalhadores dispõem” (MARX, 1988a, p. 199).

12 É por isso que Plum irá afirmar que "Marx não poderia ter podido prever tal conseqüência da técnica da higiene social, apesar de que seu adversário Malthus tenha pressentido muito tempo antes a influência da moderna higiene social sobre a multiplicação da população" (Plum, 1979, p. 202). Marx não tratou da higiene social e de outros elementos que influenciam o crescimento absoluto da população não só pelo motivo de que alguns destes tenham surgido ou se aperfeiçoado posteriormente à sua época, mas também por que em O Capital focalizava o modo de produção capitalista.

13 O próprio Nun reconhece a dificuldade dessa posição: “o que deve ficar claro é que se trata de uma distinção puramente analítica e que essas 'partes' só são separáveis no plano conceitual” (Nun, 1978, p. 100), e assim a historicidade e materialidade dos conceitos segundo o princípio metodológico de Marx (cf. VIANA, 1997; VIANA, 2001a) se perde.

14 O processo de pressão dos trabalhadores geralmente provoca a concessão, por parte da classe capitalista, de benefícios para os trabalhadores (cf. NAVARro, 1995; VIANA, 1999).

15 "O estudo de Phillips consagra enfim a impossibilidade de o capitalismo realizar qualquer forma de pleno emprego. A partir daqui a afirmação da necessidade do 'volante de desempregados' será mais hesitante, e a existência de 6\% de desempregados nos Estados Unidos ou 3 a 4 \% na Europa será considerada menos 'natural”' (BeLLON, 1975, p. 64).

\section{Referências}

BELLON, Bertrand. Desemprego e capital. Porto: A Regra do Jogo, 1975.

ENGELS, Friedrich. Anti-Dühring. 3. ed. Rio de Janeiro: Paz e Terra, 1990.

FANON, Frantz. Os condenados da terra. ed. Rio de Janeiro: Civilização Brasileira, 1979. 
MARX, Karl. As lutas de classes na França (1848-1850). São Paulo: Global, 1986.

MARX, Karl. Elementos Fundamentales Para La Crítica de la Economia Política (Grundrisse). v. 2, 10. ed. México: Siglo Veintiuno, 1985.

MARX, Karl. O capital. v. 1. ed. São Paulo, Nova Cultural, 1988a.

MARX, Karl. O capital. v. 2. ed. São Paulo, Nova Cultural, 1988b.

MARX, Karl. Teorias da mais-valia. v. 2, São Paulo: Difel, 1983.

NAVARRO, Vicente. Produção e estado de bem estar: O contexto das reformas. In: Laurell, A. (Org.). Estado e políticas sociais do neoliberalismo. São Paulo: Cortez, 1995.

NUN, José. Superpopulação relativa, exército industrial de reserva e massa Marginal. In: Pereira, Luiz (Org.). Populações marginais. São Paulo: Duas Cidades, 1978.

PLUM, Werner. Discussões sobre a pobreza das massas nos princípios da Industrialização. Bonn: Fundação Friedrich Ebert, 1979.

VIANA, Nildo. Capital, espaço e desigualdade. In: Boletim Goiano de Geografia v. 21. n. 1, jan./dez., 2001.

VIANA, Nildo. Escritos metodológicos de marx. Goiânia, Alternativa, 2006.

VIANA, Nildo. Inspeção do trabalho: tendências contemporâneas. In: Dal-Rosso, Sadi (Org.). A Inspeção do trabalho. Brasília: Sinait, 1999.

NILDO VIANA - Doutor em sociologia pela UnB e professor dos cursos de geografia e história da Universidade Estadual de Goiás, Anápolis. 